\title{
Erthroplasia of queryat- A case report
}

\author{
R.B.K. Ghimire', M. Mathur ${ }^{2}$ \\ ${ }^{1}$ Resident, ${ }^{2}$ Professor, College of Medical Sciences, Bharatpur, Chitwan
}

\begin{abstract}
Erthroplassia of Queryat (EQ) is a rare squamous cell carcinoma in situ of the penis. It usually occurs on the glans penis and appears as a well-marginated erythematous velvety patch or plaque. Here, we present a case of Erthroplasia of Queryat (EQ).
\end{abstract}

Keywords : Erthroplassia of Queryat, squamous cell carcinoma in situ, glans penis.

\section{Introduction}

Erthroplassia of Queryat (EQ) is a rare squamous cell carcinoma in situ of the penis. ${ }^{1}$ It usually occurs in uncircumscibed male between the ages 20 to 80 years old. Clinically it appears as a well-marginated erythematous velvety patch or plaque on the glans penis and prepuce or the uerthra. ${ }^{2}$ Histologically, it presents with acanthosis with elongation and thickening of rete ridges, epidermal cells lie in complete disorder with atypical cells showing large hyperchromatic nuclei. An occasional finding is vacuolization of cells usually in upper portion of epidermis. ${ }^{3}$ Treatment options include surgical excision, topical imiquimod, 5-fluorouracil, carbondioxide laser and radiation therapy. ${ }^{4}$

\section{Case Report}

A 44 years old male presented with multiple erosions and ulceration over glans penis and prepuce since 2 years. He was treated at multiple occasions with topical and oral medications, which did not relieve his symptoms. There was no vesiculation over the genitals or urethral discharge. The patient doesn't give history

Correspondence: R.B.K. Ghimire

E-mail:sevendecember@hotmail.com of any extramarital contact. On examination, there were multiple erosions throughout the circumference of glans penis with glistening appearance and prepuce. There were few shallow ulcers over dorsum of glans penis.(Fig1.) Regional lymph nodes were not palpable and there were no any oral or cutaneous lesions. Circumcision was done and the skin was sent for histopathology. Biopsies was also taken glans penis which showed disarray of cells with large, round atypical cells with hyperchromatic nuclei. Some vacuolated cells were also seen.(Fig2)

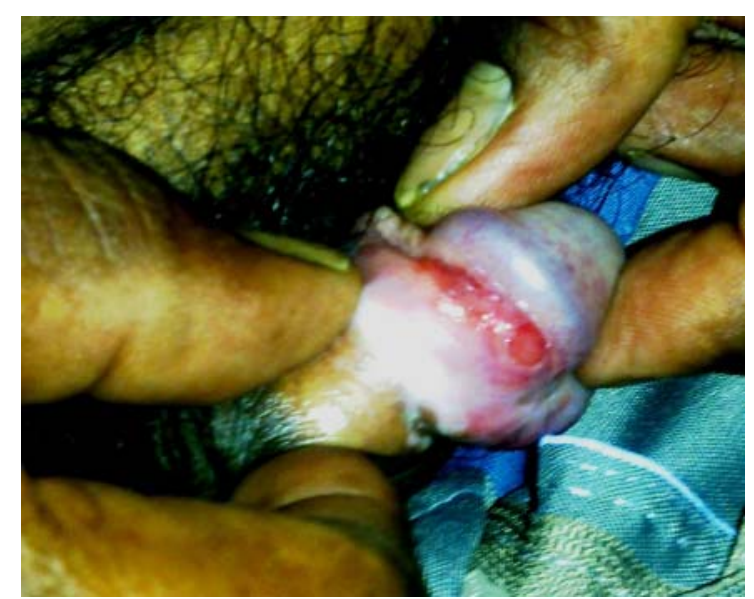

Fig. 1- Multiple erosions over glans penis and prepuce with few shallow ulcers over dorsum of glans penis. 


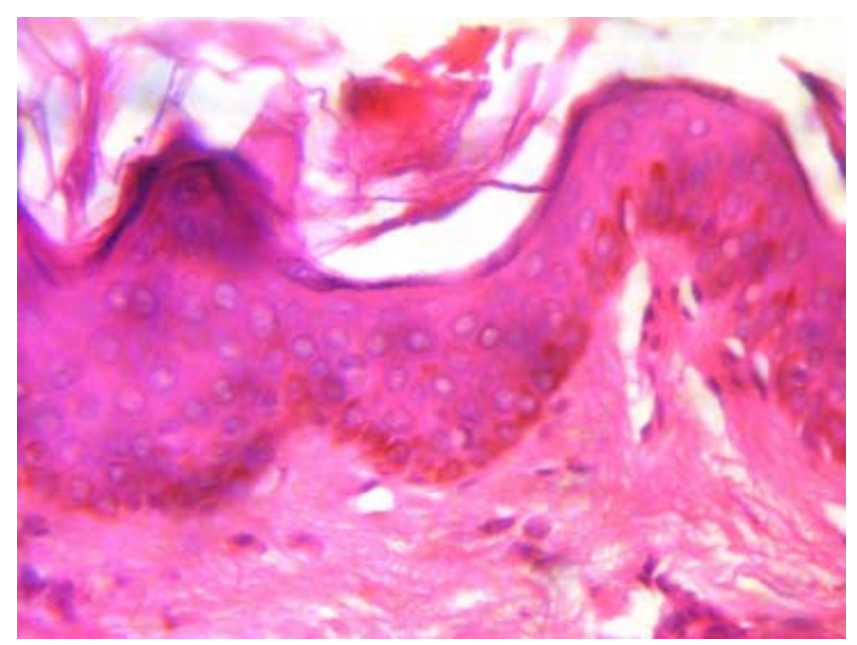

Fig2. Histopathology showing disarray of cells with large, round atypical cells with hyperchromatic nuclei and some vacuolated cells.

\section{Discussion}

EQ is the squamous cell carcinoma in situ on the mucosal or transitional surfaces of the penis. ${ }^{1}$ The disease was originally described by Tarnovsky in 1891 and subsequently was appreciated as a penile disease by Fournier and Darier in 1893. More intensive studies by Queyrat in 1911 allowed erythroplasia of Queyrat to be accepted as a distinct entity. It was first described in 1911 by L. Queyrat as "erythroplasie du gland". Sulzberger and Satenstein in 1933 recognized erythroplasia of Queyrat to be a form of carcinoma in situ. ${ }^{5}$ It manifests itself as a red shiny patch or plaque limited to the glans, coronal sulcus, and prepuce. It begins as a solitary plaque in approximately 50 $\%$ cases, and as multiple plaques in remainder. Affected males complaint of localized pain, pruritis, difficultry retracting foreskin, bleeding and crusting. ${ }^{2}$
Similar to EQ, Bowen's disease (BD) is used to refer to squamous carcinoma in situ at other cutaneous sites. EQ should be used to describe red shiny patches or plaques of the 'mucosal' penis (glans and prepuce of the uncircumcised). BD should be used to describe red, sometimes slightly pigmented, scaly patches and plaques of the keratinized penis. This distinction has not always been made in the literature. Bowenoid papulosis (BP) is analogous to, but clinically different from, EQ and BDP. The term should be used to describe multiple warty lesions, which are often pigmented in keratinized sites, and more numerous and more inflamed at 'mucosal' sites. ${ }^{6}$

Progression to an invasive SCC has been observed in up to $33 \%$ of cases of EQ, with metastases occurring in about $20 \%$ of patients with invasive carcinoma. ${ }^{7}$ In contrast, progression to invasive SCC from BD was seen in approximately $3 \%$ for cutaneous and $10 \%$ for genital lesions. It is suggested that EQ has a greater chance of becoming a malignancy than BD of the skin. ${ }^{8,9}$

The definitive etiology of EQ is still unknown, but HPV 16 is probably responsible for a significant percentage of cases. In EQ, a strong association with HPV 16 was reported by previous studies and coinfection by HPV type 8 with types 16,39 and 51 also have been identified. ${ }^{10}$

Treatment options include surgical excision, topical imiquimod, 5-fluorouracil. Carbondioxide laser and radiation therapy have also been useful in treatment of EQ. ${ }^{4,11,12,13,14}$ 


\section{References}

1. J.W. Choi, M. Choi, K.H. Cho. A Case of Erythroplasia of Queyrat Treated with Imiquimod 5\% Cream and Excision. Ann Dermatol. 2009; 21(4): 419-22.

2. K.O. Duncan, J.K. Geisse, D.J. Leffel. Epithelial precancerous lesions. In: K. Wolff, L.A. Goldsmith, S.I. Katz et al. Fitzpatricks's Dermatology in General Medicine 7th Edition-New York: McGrawHill Companies,USA.2008: 1007-27.

3. N. Kirkham. Tumors and cysts of the epidermis. In: D.E. Elder,R. Elenitsas, B.L. ohnson, G.F. Murphy, X. Xu. Lever's Histopathology of the skin 10th edition-Wolters Kluwer Health, USA.2010:851-910.

4. J.P. Arlette. Treatment of Bowen's disease and erythroplasia of Queyrat. Br J Dermatol. 2003;149 Suppl 66:43-9.

5. D.K. Goette. Review of erythroplasia of Queyrat and its treatment. Urology. Oct 1976;8(4):311-5.

6. C.B. Bunker, S.M. Neill. The Genital, Perianal and Umbilical Regions. In: T. Burns, S. Breathnach, N. Cox, et al. Rook's Textbook of Dermatology. 8th editionBlackwell Publishing, UK. 2010; 71.1-102

7. G.R. Mikhail. Cancers, precancers, and pseudocancers on the male genitalia. A review of clinical appearances, histopathology, and management. J Dermatol Surg Oncol. 1980;6:1027-35.
8. E.S. Peterka, F.W. Lynch, R.W. Goltz. An association between Bowen's disease and internal cancer.Arch Dermatol. 1961;84:623-9.

9. G.F. Kao. Carcinoma arising in Bowen's disease. Arch Dermatol. 1986;122:1124-6.

10. U. Wieland, S. Jurk, S. Weissenborn et al.. Erythroplasia of queyrat: coinfection with cutaneous carcinogenic human papillomavirus type 8 and genital papillomaviruses in a carcinoma in situ. $J$ Invest Dermatol. 2000;115(3):396-401.

11. G. Micali, M.R. Nasca, R. D. Pasquale. Erythroplasia of Queyrat treated with imiquimod 5\% cream. J Am Acad Dermatol. Nov 2006;55(5):901-3.

12. J.S. Conejo-Mir, M.A. Munoz, M. Linares et al.. Carbon dioxide laser treatment of erythroplasia of Queyrat: a revisited treatment to this condition. $J$ Eur Acad Dermatol Venereol. 2005;19(5):643-4.

13. I. Orengo, T. Rosen, C.K. Guill. Treatment of squamous cell carcinoma in situ of the penis with 5\% imiquimod cream: a case report. $J$ Am Acad Dermatol. 2002;47:Suppl 225-8.

14. W.M. Porter, N. Francis, D. Hawkins et al. Penile intraepithelial neoplasia: clinical spectrum and treatment of 35 cases. Br J Dermatol. 2002;147(6):1159-65. 